\title{
Towards A System-Based Model For Overall Performance Evaluation In A Supply Chain Context
}

\author{
Lamia Berrah $^{1}{ }^{*}$ and François Vernadat ${ }^{2}$ \\ ${ }^{1}$ Listic, Université de Savoie, BP 80439, F-74944 Annecy-Le-Vieux cedex, France \\ ${ }^{2}$ Lgipm, Université Paul Verlaine de Metz, Ile du Saulcy, F-57045 Metz cedex 1, France
}

\begin{abstract}
The paper deals with the wide issue of overall performance expression of a system made of interacting entities. Formal aspects of overall performance expression are considered as a first step of this reflection in the context of supply chains (SC's). Indeed, a SC being a network of interconnected business entities, it is proposed to consider it as a system of systems. Because system behavior depends on process dynamics, the performance of any company of the SC highly depends on the performance of its processes. However, while process performance is clearly defined in the literature, performance of complex systems or systems of systems is more difficult to assess due to process interactions. The overall performance concept is usually unsatisfactory either for each company or for the whole SC. To express such performance in SC's, recent proposals have focused on the performance of the prime manufacturer. This performance being linked to the ones of the suppliers, the impact of supplier performances on the prime manufacturer performance has to be integrated. It is therefore proposed to respectively use the SCOR model for describing the involved sub-system processes and, from a computational point of view, to use the MAUT (Multi Attribute Utility Theory) MACBETH methodology to consistently compute the expected performances. More specifically, the Choquet integral is used as the aggregation operator to handle interactions between systems and processes. The case of a bearings manufacturer is used to illustrate the proposal for a supplier selection problem.
\end{abstract}

Keywords: Performance expression, Supply chain context, Systemic approach, SCOR model, MACBETH methodology, Choquet Integral.

\section{INTRODUCTION}

The aim of any manufacturing company is to make products in order to sell them and make benefits. Due to the sophistication of products, most companies can no more produce alone all the required components. They either buy many of these items from suppliers or they subcontract part of the operations to industrial partners. Companies being dynamic systems that evolve according to their process behavior, the exchange of materials and information among them can be materialized by the different interactions which occur between the system processes. More particularly, the prime manufacturers together with their suppliers and vendors are thus forming so-called networked organizations [1], [2]. From a manufacturing and logistics point of view, this kind of network is called a supply-chain (SC) [3-6]. A SC "connects via vendor-customer relationships the ultimate customer to the ultimate supplier" [7]. In this sense, the SC can be defined as "the life cycle processes comprising physical, information, financial and knowledge flows whose purpose is to satisfy end-user requirements with products and services from multiple linked suppliers" [8].

From a general point of view, a SC being the operational process model of a "system of systems", several activities

*Address correspondence to this author at the Listic, Université de Savoie, BP 80439, F-74944 Annecy-Le-Vieux cedex, France; Tel: +33 450096 582; Fax: +33 450096 559; E-mail: lamia.berrah@univ-savoie.fr can be associated to it in terms of system life cycle. For instance, Meixell and Gargeya [9] worked on the SC design, Luo et al. [10] and $\mathrm{Wu}$ and Olson [11] dealt with supplier and vendor selection maintenance and notably manufacturing while Ayers [8] handled the satisfaction of end-user needs. Several proposals have also been made with regard to the modeling aspects [12-17]. In this context, the SCOR (Supply Chain Operations Reference) model [18] suggests to distinguish four abstraction levels, from the more generic (level 1) to the more particular (level 4) (Fig. 1).

In our view, the SCOR model is just an abstract representation of the life-cycle of the SC, from the design step to the implementation one. The SCOR model thus provides a kind of instantiation mechanism of the systems that are involved in the overall SC, although the proposed SCOR paradigm remains vertical.

In addition, an important point in the SC management concerns the expression of the reached performances ([1923]). Indeed, performance assessment helps decision-makers to manage the SC and explain the achieved result, to compare different organizations (e.g., the choice of the transport system) or to make benchmarks of whole or part of the SC (e.g., the delivery reliability is worse than the median). Besides, the expression of the SC performance remains a difficult task [24-27]. It is usually handled in two ways, respectively considering the $\mathrm{SC}$ performance as: 


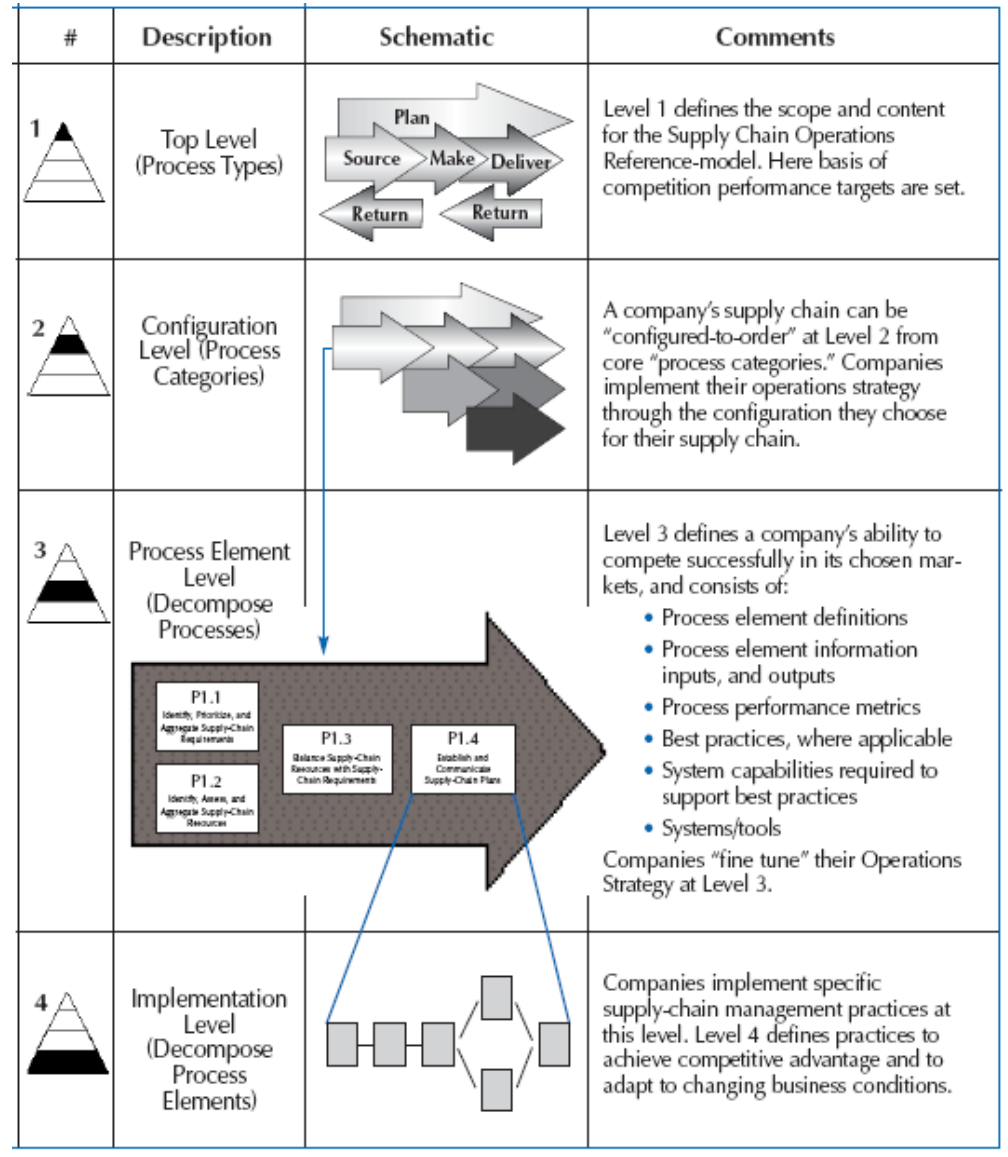

Fig. (1). The SCOR model [18].

- a company's performance, by taking into account the intra-organizational evaluation [28-30] of the different partners of the SC on the one hand and the evaluation of the interactions between the different companies on the other hand [31, 32].

- related to the performance of the process that results from the processes of the different involved companies, according to the recommendations of the ISO 9001 standard [33]. Note that SCOR has been conceived with this logic in mind. Due to the central role of the prime manufacturer in the SC management, his point of view is often considered.

Note that despite their overall aspect, both approaches do not cover the overall SC performance expression, by focusing on one central company and considering the operational processes that constitute the SC.

Moreover, two basic assumptions are made in these two visions concerning the $\mathrm{SC}$ break-down. The first assumption concerns company break-down, while the second one concerns functional break-down. But, from a systemic point of view, the SC being a network of interconnected business entities executing SC processes, it can be seen as a system of systems or SoS [34-37]. Indeed, each participating business entity is itself a system with its own structure, behavior, organization, autonomy and performance. The real challenge is thus to manage the whole SC as one collaborative system made of cooperative processes. Indeed, this implies communication, synchronization, coordination and even negotiation activities. By focusing on the prime manufacturer point of view as the coordinating element, it has been decided to adopt in this paper a systemic approach combined with the SCOR model to devise a performance evaluation approach. To be more precise, considering an existing SC with the different involved company processes, we assume a handling of the prime manufacturer process, which interacts with the implied supplier processes. Thus, systems made of heterogeneous systems, in which each sub-system is described in terms of its constituting business processes, can be analyzed.

Furthermore, the two usual types of decisional performance, strategic and operational, are usually treated separately. The interactions between them are seldom addressed both in the literature and in practice, leading decision-makers to intuitively synthesize the set of available performance elements, eventually ignoring the explanation of the strategic results from the operational actions and partially taking into account the overall objectives break-down and the conjectural events [38]. These limitations can be handled by looking for an overall performance expression. Such expression would also be strategic, retrospectively obtained by linking the operational expressions. Being indirect, this expression could thus be compared to the direct conventional one. Like it is the case for the expression of the overall performance of a single company, the overall expression of the prime manufacturer performance in a SC context requires the operational evaluations of the constitutive processes, which are called elementary performance expressions, as well as the identification of the interactions between these expressions with 
regard to the overall ones, namely the additional identification of the interactions between the sub-systems, i.e., the involved companies or business entities.

To express overall performance, the major frameworks used in the Performance Measurement System (PMS) literature come from the aggregation model line of thought [39]. In this approach, aggregation operators are used such as the weighted arithmetic mean (WAM) to handle hierarchical interactions or the Choquet integral (CI) to take more generalized interactions into account [40-42]. Moreover, methodologies based on the Multi-Attribute Utility Theory have also been pointed out [43] such as the Analytic Hierarchy Process AHP [44-46] or the Measuring Attractiveness by a Categorical Based Evaluation TecHnique MACBETH [47]. As shown in several previous papers, these methodologies consistently define both the elementary performance expressions and parameters of the aggregation operators [29, 32, 48].

This study provides formal elements for the expression of the overall SC performance. At this step, an extension of what can be done for a single overall company process performance is adopted and strong limitations are fixed, namely the only consideration of the prime manufacturer point of view, thus reducing the set of decision-makers to only one. On the other hand, the interactions between the different involved processes are introduced with regard to a systemic point of view of the SC. Formally, the work deals with the prime manufacturer performance quantification issue in a $\mathrm{SC}$ context. It builds on previous works performed by Berrah and Clivillé $[49,32]$, respectively by considering the Choquet Integral (CI) aggregation for the handling of the mutual interactions and the MACBETH ${ }^{1}$ method for a consistent expression of the performance.

The paper is organized as follows. Section 2 first presents the systemic approach in which the SC is defined as a SoS and then Section 3 focuses on the major SCOR model principles. Section 4 presents a formalization of the performance expression problem. The MACBETH method and the CI are thus illustrated through the expression of the SCOR Source process performance. Then, in Section 5, a case study concerning a bearings manufacturer is used. The problem is about how to handle the impact of supplier performances in the expression of this prime manufacturer performance. Some concluding remarks and perspectives are finally proposed.

\section{SUPPLY CHAINS AS SYSTEMS OF SYSTEMS}

A SC is a networked organization that can be depicted as an oriented graph, the nodes of which are business entities and the arcs of which represent either material flows or information flows connecting nodes. Each business entity is part or whole of a given SC partner enterprise (supplier, subassembler, final assembler, logistics unit, distributor or retailer). From a systemic point of view, each business entity is a system on its own (i.e., made of a physical system, an information system and a decision system). It is well-known that the complexity of a system is a function of the number of its components (i.e., business entities for the SC) and the

${ }^{1}$ Further justification arguments about the CI and the MACBETH method can be found in $[42,47,61]$. number of interactions among the components and their environment (i.e., material, information, decision and control flows). This gives an idea of the potential complexity of a SC.

It can be argued that any SC complies in any point with the definition of a System of Systems (SoS) as defined by Ackoff [34] or Maier [35]. Indeed, according to Maier [35], the concept of SoS differs from the one of monolithic system on the basis of five fundamental principles which are:

- operational independence of components: if component systems of a SoS are separated, they can still work independently;

- managerial independence of components: component systems are acquired separately and integrated to the SoS in which they can be managed independently;

- evolutionary development: a SoS is never totally complete; its structure evolves according to addition, suppression or modification of component systems to fulfill the SoS goals;

- emerging behavior: constituent systems, evolving over time, have the ability of self-organization in order to ensure the continuity of the mission of the overall SoS;

- geographic distribution: component systems can be physically distributed in space.

Boardman and Sauser [50] have recently revisited these principles and arranged them as follows.

- Autonomy: autonomous components contribute to the SoS finality.

- Emergence: the behavior of a SoS is not strictly prescriptive but emerges from the behavior of component systems and stimuli of the SoS environment.

- Connectivity: the efficiency of a SoS depends on the connectivity and interoperability of component systems.

- Diversity: a necessary condition to the existence of a SoS is the heterogeneity of its constituents.

- Belonging: component systems decide to belong to the SoS on a cost/benefit basis, to get profit on their own and because they have trust in the mission of the SoS.

Obviously, each of these principles conforms to the definition of a SC. The autonomy property relates to the independent characteristic of each participating company, the definition of its own objectives and the means required to achieve them. Nevertheless, all the companies contribute to the achievement of the common objectives, i.e. the SC ones. This set of common objectives is necessary to define a SC, making each company a real partner of this virtual company. From a dynamic point of view, the evolution of a SC can be deterministic with regards to some structural aspects such as its involved activities, but remains dependent on the context and the occurring events. Moreover, each company is connected to the others, in the form of supplier-customer relationships, and each company is involved in the SC with regard to its proper contribution, thus contributing to the diversity and complementarity dimensions. 
Table 1. SC Performance Measurement Framework [62]

\begin{tabular}{|c|c|c|c|}
\hline SC Process & Strategic & Tactical & Operational \\
\hline Plan & $\begin{array}{l}\text { Level of customer perceived value of product, } \\
\text { Variances against budget, Order lead time, } \\
\text { Information processing cost, Net profit vs. } \\
\text { productivity ratio, Total cycle time, Total } \\
\text { cash flow time, Product development cycle } \\
\text { time }\end{array}$ & $\begin{array}{l}\text { Customer query time, Product development } \\
\text { cycle time, Accuracy of forecasting tech- } \\
\text { niques, Planning } \\
\text { process cycle time, Order entry methods, } \\
\text { Human resource productivity }\end{array}$ & $\begin{array}{l}\text { Order entry methods, Human resource } \\
\text { productivity }\end{array}$ \\
\hline Source & & $\begin{array}{l}\text { Supplier delivery performance, Supplier lead } \\
\text { time against industry norm, Supplier pricing } \\
\text { against market, Efficiency of purchase order } \\
\text { cycle time, Efficiency of cash flow method, } \\
\text { Supplier booking in procedures }\end{array}$ & $\begin{array}{l}\text { Efficiency of purchase order cycle time, } \\
\text { Supplier pricing against market }\end{array}$ \\
\hline $\begin{array}{c}\text { Make/ } \\
\text { Assemble }\end{array}$ & $\begin{array}{c}\text { Range of products and services Percentage of } \\
\text { defects, Cost per operation hour, Capacity } \\
\text { utilization, }\end{array}$ & Utilization of economic order quantity & $\begin{array}{l}\text { Percentage of Defects, Cost per operation } \\
\text { hour, Human resource productivity index }\end{array}$ \\
\hline Deliver & $\begin{array}{c}\text { Flexibility of service system to meet customer } \\
\text { needs, Effectiveness of enterprise distribution } \\
\text { planning schedule }\end{array}$ & $\begin{array}{l}\text { Flexibility of service system to meet cus- } \\
\text { tomer needs, Effectiveness of enterprise } \\
\text { distribution planning schedule, Effectiveness } \\
\text { of delivery invoice methods, Percentage of } \\
\text { finished goods in transit, Delivery reliability } \\
\text { performance }\end{array}$ & $\begin{array}{l}\text { Quality of delivered goods, On time delivery } \\
\text { of goods, Effectiveness of delivery invoice } \\
\text { methods, Number of faultless delivery notes } \\
\text { invoiced, Percentage of urgent deliveries, } \\
\text { Information richness in carrying out delivery, } \\
\text { Delivery reliability performance }\end{array}$ \\
\hline
\end{tabular}

Nota bene: The Return process is not included in this Table because it was not part of the definition of the first version of the SCOR model.

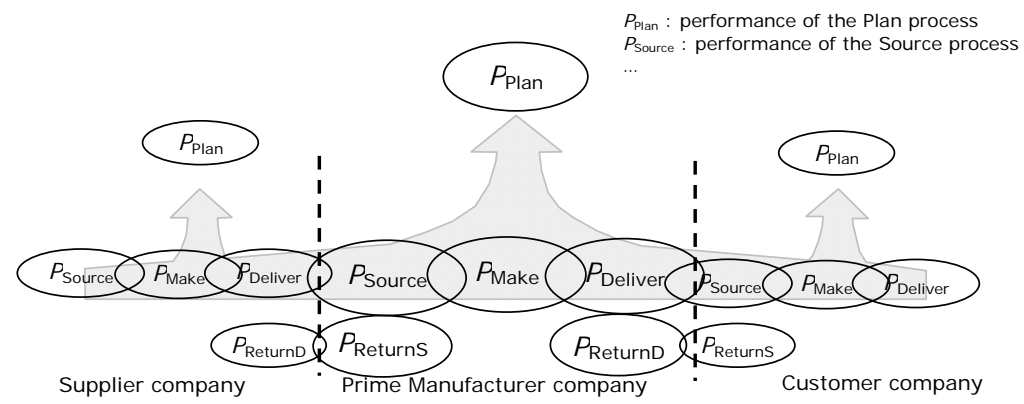

Fig. (2). The overall SC performance structure.

From a systemic and SoS point of view, the SC performance can be obtained from the combination of the individual performances contributed by the participating companies, namely the prime manufacturer and all its suppliers and partners. Moreover, the performance of each company can be identified as the performance of its operational processes, although each company still has its own way of defining its objectives and expressing its performances. In this context, the SCOR model is considered because it offers a standardized and well-known framework for representing the different system processes involved in the supply chain.

\section{THE SCOR MODEL}

The SCOR model $[18,51,52]$ has become a crossindustry de-facto standard in supply chain management practices. It is structured in four levels (Fig. 1). At level 1, each company of the SC is described in terms of five generic processes: Plan - Source - Make - Deliver - Return. At level 2, these processes are further specified according to the global SC objectives (e.g. the Source process is identified in the S1 process i.e. Source Stocked Product, or the S2 process i.e. Source Make-to-Order Product or the S3 process i.e.
Source Engineer-to-Order Product). At level 3, the processes of level 2 are broken down into sub-processes according to the company's organization. At level 4, the activities, which constitute the sub-processes, are specified according to the organization of the company (level 4). The SCOR model identifies a tree process structure with regard to the five main processes illustrated in Fig. (1). Performance indicators are thus built in order to supply performance information for each process at each decision level (Table 1). As an illustration of the SC sub-systems interactions, one can note that the Source performance of the prime manufacturer depends on the Deliver supplier performance (Table $\mathbf{1}$ and Fig. 2).

\section{PERFORMANCE EXPRESSION ISSUE}

A basic assumption made in this section is that the overall performance expression can be computed from the combination of elementary performances. These elementary performances are directly linked to processes of the different subsystems being considered. A formalization of the aggregation method is presented before considering the definition of the elementary performance and then of the aggregated one. 


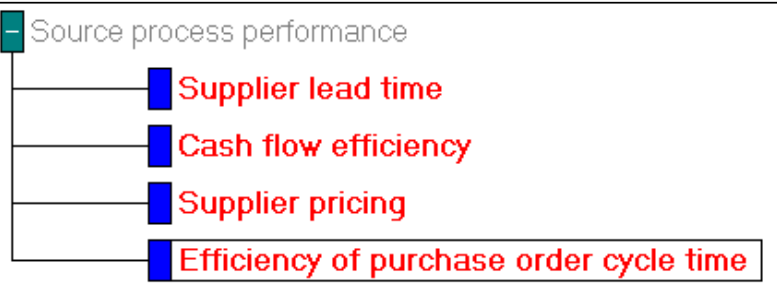

Fig. (3). The Source Process criteria.

More particularly, two points of view of the performance expression are discussed. A formal definition of the respective aggregated and elementary performances is proposed in Sub-sections 4.1 and 4.2. Focusing in this study on the overall performance expression mechanism, the assumptions concern first the necessity of taking into account the interactions between the expressions to be aggregated. Moreover, according to the measurement theory [53], we consider that if an elementary performance is expressed in the view of aggregating it, it has to satisfy the "commensurability" condition on the one hand and the "significance" of the aggregation operator on the other hand [41]. The commensurability relates to something like the homogeneity of the different performances to be aggregated. The significance concept identifies the semantics of the obtained scales (e.g., interval scale, ratio scale...). Recently, Grabisch et al. have published comprehensive surveys on aggregation functions and their mathematical properties, which include a number of references [54, 55]. In Sub-sections 4.3, 4.4 and 4.5, the aggregation operator is presented and illustrated by an example. The CI operator is considered to take into account the elementary interactions. The MACBETH framework is used to consistently express the elementary performances and characterize the operator parameters.

\subsection{The Performance Aggregation Operation}

Performance aggregation is a specific form of information aggregation [56]. It is seen as an operation that synthesizes the elementary performance expressions into an overall one [57]. The difference between the concepts of "elementary" and "aggregated" is in the computation mode. While an elementary expression is "directly" expressed from the reached measure, the aggregated one is "indirectly" expressed from the set of elementary performances. The aggregation becomes a mechanism for expressing overall performances, as it is the purpose of PMS's. Hence, the performance aggregation is defined by the mapping $A_{g}$ such as [41]:

$$
\begin{gathered}
A_{g}: E_{1} x E_{2} x \ldots x E_{n} \rightarrow E \\
\left(p_{1}, p_{2}, \ldots, p_{n}\right) \rightarrow p_{A g}
\end{gathered}
$$

The $E_{i}{ }^{\prime} s$ are the domains of the expressions $\left(p_{1}, p_{2}, \ldots, p_{n}\right)$, i.e., the sets of values of the elementary performances, and $E$ is the domain of $p_{A g}$, i.e., the set of values of the aggregated performance. Since $E_{i}$ 's and $E$ can be different, the determination of $A_{g}$ is not easy to obtain.

Example: Let us consider a simple example (extracted from the bearings manufacturing case used in the paper). Let us assume a SCOR representation, more specifically focusing on the Source process. To compare its different suppli- ers, let us consider that the prime manufacturer needs to express the performances related to the four following criteria (selected from Table 1): the Supplier_lead_time, the Cash_flow_efficiency, the Supplier_pricing and the Efficiency_of_purchase_order_cycle_time (Fig. 3).

For a given supplier, let us assume the following measures: $m_{1}=12$ days for the Supplier_lead_time, $m_{2}=3$ months for the Cash_flow_efficiency, $m_{3}=13, \overline{5} €$ for the Supplier_pricing and $m_{4}=98 \%$ for the Efficiency_of_purchase_order_cycle_time. One way to get the supplier performance is to proceed to the aggregation of the previous measures. However, these pieces of information are given in different units. One classical way to correctly address aggregation is first to translate the measures into satisfaction degrees. The relation between the so-called elementary performance expressions and the overall one must then be defined. The weighted sum (WAM) operator for instance is generally used. Thus, $p_{A g}=w_{1} p_{1}+w_{2} p_{2}+w_{3} p_{3}+w_{4} p_{4}$, where $w_{i}$ is the weight of the expression $p_{i}$ in $p_{A g}$. It should be noted that in the case of a SoS, the same performance measurement can be locally expressed in totally different analytical ways for two different companies, e.g., for two different suppliers, in terms of elementary performance expressions and still be possible to be aggregated at the SC level. This leaves room for local differentiation or adaptation within each company which has its own methods or knowhow on performance expression. Elementary performance expressions are explained in the next section.

\subsection{Elementary Performance Expression}

The translation of physical measures into performance expressions can be generally described by the mapping $P$ [58] such as:

$$
\begin{aligned}
& P: O x M \rightarrow E \\
& \quad(o, m) \rightarrow P(o, m)=p
\end{aligned}
$$

$O, M$ and $E$ are respectively the domains i.e., the set of values of objectives $o$, the measures $m$ and the performance expressions $p$. The major difference between such performance expressions from traditional measurements is the comparison of the acquired measures with the considered objectives. This approach is strongly inspired from the Taylorian ratios, in accordance with performance indicator concepts, which can be defined as: "A performance indicator is a variable indicating the effectiveness and/or efficiency of a part or whole of the process or system against a given norm / target or plan" [59]. The mapping $P$ denotes a comparison operator such as a distance or a similarity operator [58], thus leading to an assessment expression of the reached results.

In addition, when human knowledge is available, rather than using a direct comparison operator, the MACBETH method can be used to coherently translate this knowledge into numerical assessments, which are defined on interval scales such as [0,1]. In MACBETH [29], the elementary performances as well as the aggregation operator (WAM) parameters are defined from human comparisons between different situations, which are related to the conjuncture, such as the worst one, the best one, the one in which one performance is totally satisfied and not the others... According to the measurement theory [53], the approach consists in translat- 


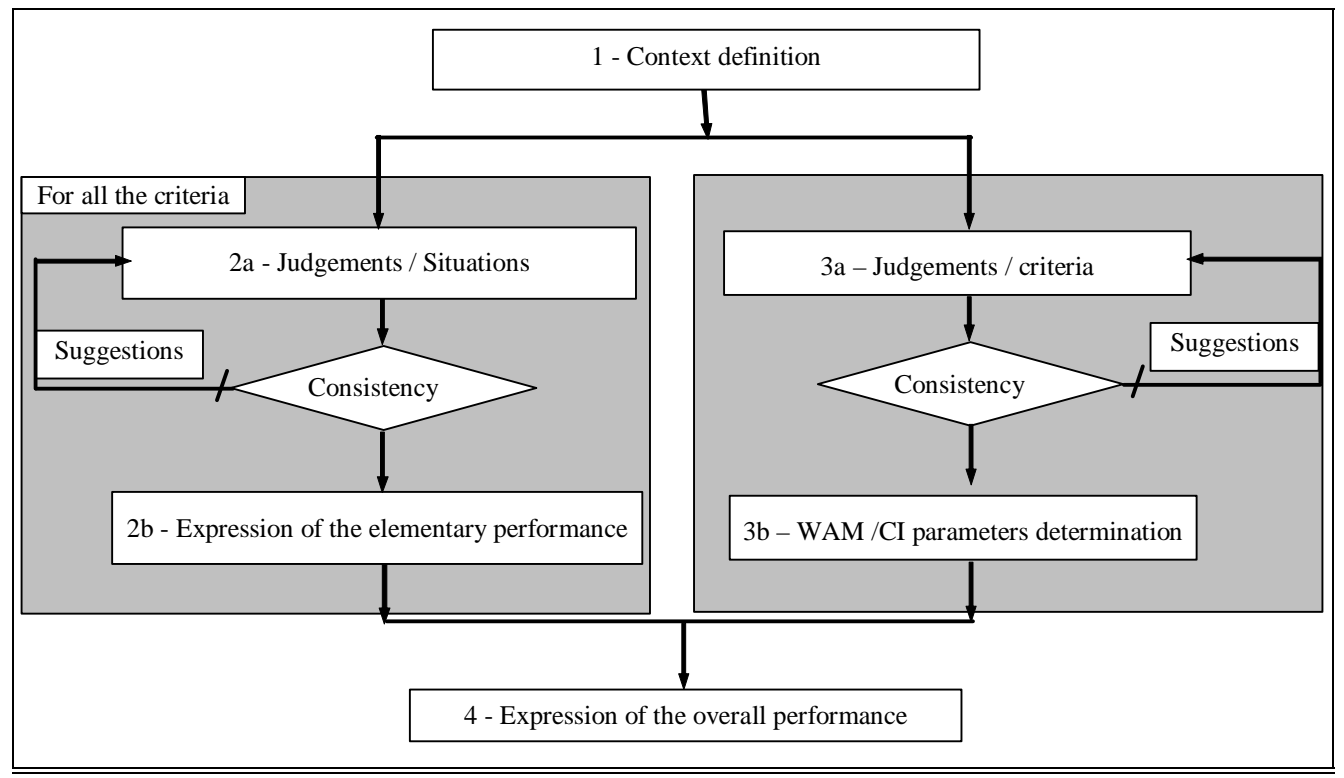

Fig. (4). MACBETH Procedure for the Performance Expression.

Table 2. The Decision-Maker's Judgments About Supplier_Lead_Time

\begin{tabular}{|c|c|c|c|c|c|}
\hline \multicolumn{4}{|c|}{ Mn Supplier lead time } & \multicolumn{2}{|r|}{$\underline{x}$} \\
\hline 盽 & Good & $\mathrm{S} 2$ & s1 & S3 & Neutral \\
\hline Good & no & $?$ & positive & positive & positive \\
\hline $\mathrm{S} 2$ & $?$ & no & weak & positive & positive \\
\hline S1 & & & no & strong & positive \\
\hline 53 & \multirow{2}{*}{\multicolumn{3}{|c|}{$\begin{array}{l}\text { SC manager strongly prefers } \\
\text { supplier S1 to supplier S3 }\end{array}$}} & no & v. strong \\
\hline Neutral & & & & & no \\
\hline
\end{tabular}

ing the judgments about the set of situations into quantitative information (Fig. 4). The concepts of preferences and strengths of preference are used, being handled by qualitative levels of attractiveness (e.g., null, very weak, weak, moderate, strong, very strong or extreme) [60].

Example: Considering the previous example ( $\S 4.1$ ), Table 2 describes the judgments of the prime manufacturer decision-makers concerning the Supplier_lead_time criteria with respect to three different steel furniture suppliers, SI, $S 2$, and $S 3$. In this case, the decision-maker is not fully satisfied with $S 3$ and wants to compare it with the two other suppliers ( $S 1$ and $S 2$ ). Note that, for the consistency of the procedure, two fictive suppliers are introduced in the Table: "Supplier Good", which entirely satisfies the prime manufacturer, and "Supplier Neutral", which does not satisfy at all.

The MACBETH method is used to compute the elementary performances according to the resolution of a linear equation system (e.g., the performance of $S 2$ concerning Supplier_lead_time is 0.69 ). Table 3 summarizes the decision-makers judgments on the other situations.

According to the obtained scorecard, the decision-makers can analyze their Source process by considering the strengths and the weaknesses of each supplier. But if they want to rank their suppliers, an overall evaluation is required, because
Table 3. The Elementary Performance Expressions

\begin{tabular}{|c|c|c|c|c|}
\hline & $\boldsymbol{p}_{\mathbf{1}}$ & $\boldsymbol{p}_{\mathbf{2}}$ & $\boldsymbol{p}_{\mathbf{3}}$ & $\boldsymbol{p}_{\mathbf{4}}$ \\
\hline \hline Supplier $S 1$ & 0.53 & 0.69 & 0.31 & 0.50 \\
\hline S1 Ranking & 2 & 1 & 3 & 1 \\
\hline Supplier $S 2$ & 0.65 & 0.56 & 0.54 & 0.50 \\
\hline S2 Ranking & 1 & 2 & 2 & 1 \\
\hline Supplier $S 3$ & 0.29 & 0.37 & 0.85 & 0.20 \\
\hline S3 Ranking & 3 & 3 & 1 & 3 \\
\hline
\end{tabular}

there is no Pareto dominance between their performances. Rather than the WAM operator, we prefer the use of the Choquet Integral to take interactions between the involved sub-systems into account.

\subsection{The Choquet Integral Operator}

Trade-off operators are widely used for industrial aggregation. This means that the aggregated performance is necessary between the minimum and the maximum of the elementary performances. In this view, the Choquet Integral (CI) family operators [61] include generalized mean operators. These operators can be formulated as a WAM particularly taking into account the elementary interactions. More specifically, the 2-additive CI is used herein, which considers interactions by pair, and which is defined by two parameters [61]:

- the weight of each elementary performance with regards to the overall one, by the so-called Shapley parameters $v_{i}{ }^{\prime} s$, that satisfy the condition $\sum_{i=1}^{n} v_{i}=1$;

- the interaction parameters $I_{i j}$ of any pair of performance criteria, that range in $[-1,1]$;

$\circ$ a positive $I_{i j}$ implies that the simultaneous satisfaction of objectives $o_{i}$ and $o_{j}$ is significant 
for the aggregated performance, but a unilateral satisfaction has no effect;

○ a negative $I_{i j}$ implies that the satisfaction of either $o_{i}$ or $o_{j}$ is sufficient to have a significant effect on the aggregated performance;

○ A null $I_{i j}$ implies that no interaction exists.

The associated aggregation function is thus given by:

$p_{A g}=\sum_{i=1}^{n} v_{i} p_{i}-\frac{1}{2} \sum_{i, j=1}^{n} I_{i j}\left|p_{i}-p_{j}\right|$

where $\left(p_{1}, p_{2}, \ldots, p_{i}, \ldots, p_{n}\right)$ is the elementary performance vector such as $\left(v_{i}-\frac{1}{2} \sum_{j=1}^{n} I_{i j}\right) \geq 0 \quad \forall i \in[1, n]$ and $i \neq j$

and $I_{i j}=I_{j i} i \neq j$.

Note that if all $I_{i j}=0$, thus $v_{i}$ acts as the weights in a WAM. Although the CI has more parameters than the WAM, their determination is based on the same principle. For the sake of conciseness and without loss of generality, only an example is treated.

\subsection{Example of a CI Parameters Determination}

MACBETH, which has been used on the basis of the WAM, has been extended by [29] in order to consider the CI. The idea remains the same, defining knowing expert judgments:

a) the Shapley parameters $v_{i}$;

b) the interaction parameters $I_{i j}$.

For example, in the case where the elementary vector is $\left(p_{1}, p_{2}, p_{3}, p_{4}\right), v_{1}, v_{2}, v_{3}, v_{4}$ and $I_{12}, I_{13}, I_{14}, I_{23}, I_{24}, I_{34}$ have to be determined. Decision-makers compare thus some particular situations that are known through their elementary vectors previously denoted $\left(p_{1}, p_{2}, \ldots, p_{i}, \ldots, p_{n}\right)$. In this sense, simpler fictive situations are considered, where a part of the objectives is totally satisfactory, and the other part is totally non satisfactory: i.e. $p_{i}$ take respectively the values 0 or 1 . Then, the decision-makers compare the considered situations. The same "strengths of preference" than for the elementary performances are used. For instance, in the case of the previous example (\$4.1), decision-makers consider the two following aggregated expressions $p_{A g}^{(0,1,0,0)}, p_{A g}^{(0,0,1,0)}$, respectively relative to the vectors $(0,1,0,0)$ and $(0,0,1,0)$. The difference between these expressions is "extreme", i.e.: $p^{(0,0,1,0)}>^{6} p_{A_{g}}^{(0,1,0,0)}$ in which " 6 " corresponds to the "extreme" strength of preference, i.e., the decision-makers extremely prefers the situation which is described by the $(0,1,0,0)$ vector to the situation which is described by $(0,0,1,0)$. This judgment can be written by the following equations:

$$
p_{\mathrm{Ag}}^{(0,0,1,0)}-p_{\mathrm{Ag}}^{(0,1,0,0)}=6 \alpha \Leftrightarrow-v_{2}+v_{3}-\frac{1}{2}\left[-I_{12}+I_{13}-I_{24}+I_{34}\right]=6 \alpha
$$

Table 4. CI Parameters

\begin{tabular}{|c|c|c|c|c|}
\hline$v_{1}$ & $v_{2}$ & $v_{3}$ & $v_{4}$ & $I_{12}$ \\
\hline \hline$\approx 0,20$ & $\approx 0,26$ & 0,50 & $\approx 0,04$ & $\approx 0,09$ \\
\hline$I_{13}$ & $I_{14}$ & $I_{23}$ & $I_{24}$ & $I_{34}$ \\
\hline$\approx 0,04$ & $\approx 0,09$ & $\approx 0,13$ & $\approx-0,04$ & $\approx-0,04$ \\
\hline
\end{tabular}

Table 5. The Aggregated Performance Expressions

\begin{tabular}{|c|c|c|c|c|c|}
\hline & $\boldsymbol{p}_{\mathbf{1}}$ & $\boldsymbol{p}_{\mathbf{2}}$ & $\boldsymbol{p}_{\mathbf{3}}$ & $\boldsymbol{p}_{\boldsymbol{4}}$ & $\boldsymbol{p}_{\text {Ag }}$ \\
\hline \hline Supplier $S 1$ & 0.53 & 0.69 & 0.31 & 0.50 & $\mathbf{0 , 4 2}$ \\
\hline Supplier $S 2$ & 0.65 & 0.56 & 0.54 & 0.50 & $\mathbf{0 , 5 5}$ \\
\hline Supplier $S 3$ & 0.29 & 0.37 & 0.85 & 0.20 & $\mathbf{0 , 5 4}$ \\
\hline
\end{tabular}

Knowing that, by using (3):

$$
\begin{aligned}
& p_{A g}=v_{1} p_{1}+v_{2} p_{2}+v_{3} p_{3}+v_{4} p_{4}-\frac{1}{2}\left(I_{12}\left|p_{1}-p_{2}\right|+I_{13}\left|p_{1}-p_{3}\right|+I_{14}\right. \\
& \left.\left|p_{1}-p_{4}\right|+I_{23}\left|p_{2}-p_{3}\right|+I_{24}\left|p_{2}-p_{4}\right|+I_{34}\left|p_{3}-p_{4}\right|\right) \\
& p_{A g}^{(0,0,1,0)}=v_{3}-\frac{1}{2}\left(I_{13}+I_{23}+I_{34}\right) \text { and } p_{A g}^{(0,1,0,0)}=v_{2}-\frac{1}{2}\left(I_{12}+I_{23}+I_{24}\right) .
\end{aligned}
$$

To define the 10 parameters (the $4 v_{\mathrm{i}}$ and the $6 I_{\mathrm{ij}}$ ) and the parameter $\alpha, 11$ pair-wise judgments must be made, leading to 11 equations such as e.g. (5) (see Appendix 1). CI parameters for this example are presented in Table 4.

Note that the determination step of the aggregation operator parameters does not depend on what the decisionmaker has to compare or to rank. In this step, the aggregation framework is established according to the human expertise and knowledge of the decision problem context.

\subsection{The Aggregated Performance Expression}

The use of the CI leads to the expression of an overall performance for the Source process, of respectively $S 1, S 2$ and $S 3$ (see Table 5).

It is now possible for decision-makers to rank the suppliers $S 1, S 2$ and $S 3$. However, even if the best supplier is $S 2$, the difference with $S 3$ is negligible. Moreover, both the strengths and the weaknesses are identified, leading thus the suppliers thinking on their improvement. Suppliers should thus jointly improve the elementary performance expressions in the case of interaction ( $p_{2}$ and $p_{3}$ because $I_{23}=0.13$ ).

This example can be used to demonstrate decisionmakers some interesting considerations. The first one is classical and relies on one major problem handled by the MAUT, namely the ranking and selection problem, of the suppliers in this case. However, the main characteristic is more related to the diagnosis of existing situations and the simulation of alternative ones, by considering the link between the overall and the elementary performances.

\section{NUMERICAL APPLICATION}

\subsection{Problem Statement}

The proposed case study concerns the case of a bearings company. This company is the prime manufacturer of the SC that is made of suppliers and distributors. Because the com- 
Table 6. The Process Performance Expressions

\begin{tabular}{|c|c|c|c|c|}
\hline $\begin{array}{c}\text { Plan } \\
\mathbf{p}_{\mathbf{1}}\end{array}$ & $\begin{array}{c}\text { Source } \\
\mathbf{p}_{\mathbf{2}}\end{array}$ & $\begin{array}{c}\text { Make } \\
\mathbf{p}_{\mathbf{3}}\end{array}$ & $\begin{array}{c}\text { Deliver } \\
\mathbf{p}_{\mathbf{4}}\end{array}$ & $\begin{array}{c}\text { Return } \\
\mathbf{p}_{\mathbf{5}}\end{array}$ \\
\hline \hline 0,48 & 0,55 & 0,71 & 0,59 & 0,36 \\
\hline
\end{tabular}

pany is involved in the fusion with another bearings manufacturer, it is kept anonymous for confidentiality reasons. The company works in Europe for automotive and aeronautics industry as well as in spatial and other high technology operations The suppliers are on the one hand European or Asian steel producers and on the other hand SMEs specialized in precision milling and grinding. As an initial step, in accordance with the SCOR models that have been previously used for describing the $\mathrm{SC}^{2}$, the company decided to express its Source process performance in order to know if it had to keep or change its suppliers in the defined SC. The company was thus looking for a kind of evaluation mechanism of its suppliers. In the current stage, this prime manufacturer is interested in the study of all its processes that have been implemented a few years ago and still need deep improvements. Beyond the ranking of the involved suppliers, the major interest of such expression is to highlight the different interactions between the performances and their impact on the reached scores. The main focus will be on the expression of the so-called the prime manufacturer overall performance. Such a performance is defined as being the result of the aggregation of the performances related to the different processes involved in the considered SC (i.e., in the SCOR framework, Plan, Source, Make, Deliver and Return). In this context, it has been proposed to reconsider the Source process improvement through two points of view.

- Is the impact of the Source process globally significant?

- What would be the impact of a Source process improvement on the overall performance?

According to decision-makers expertise, it has thus been proposed to provide an aggregation model that establishes the links between the processes performance and the overall one.

\subsection{The Elementary Expressions of the Different Prime- Manufacturer Processes}

Decision-makers express the overall performance according to the five standard SCOR processes (cf. Fig. 2). These performances are considered as elementary ones with regard to the application problem. The approach to be used is the same than the one explained in Section 3. For the sake of conciseness, this point is not detailed and only the current performance is given according to Table 6. Let us simply note that these expressions are the result of the aggregation of four performances, respectively related to the effectiveness and the efficiency of each process. The elementary per-

\footnotetext{
${ }^{2}$ A partnership is well established between the company and the LISTIC laboratory, leading, from an academic point of view, to international publications. That is why the industrial system description is quite similar to the one given in [49]. Note moreover that for the sake of confidentiality, the considered values are purely indicative and remain the same in all the studies that concern the prime manufacturer suppliers relation.
}

Table 7. Different Improvement Scenarios

\begin{tabular}{|c|c|c|c|c|c|c|}
\hline & $\boldsymbol{p}_{\mathbf{1}}$ & $\boldsymbol{p}_{\mathbf{2}}$ & $\boldsymbol{p}_{\mathbf{3}}$ & $\boldsymbol{p}_{\mathbf{4}}$ & $\boldsymbol{p}_{\mathbf{5}}$ & $\boldsymbol{p}_{\text {Ag }}$ \\
\hline \hline $\begin{array}{c}\text { Current } \\
\text { state }\end{array}$ & 0,48 & 0,55 & 0,71 & 0,59 & 0,36 & $\mathbf{0 . 5 3}$ \\
\hline $\boldsymbol{p}_{\mathbf{2}}+$ & 0,48 & 0,65 & 0,71 & 0,59 & 0,36 & $\mathbf{0 . 5 4}$ \\
\hline $\boldsymbol{p}_{\mathbf{2}}++$ & 0,48 & 0,95 & 0,71 & 0,59 & 0,36 & $\mathbf{0 . 5 7}$ \\
\hline
\end{tabular}

formances have been obtained from the comparison of past situations concerning the supply chain experimentation.

\subsection{The Overall Performance Expression of the Prime Manufacturer}

For determining the CI parameters according to the previous example data, decision-makers compare some particular situations related to the five SCOR processes. These situations are known through their associated elementary performance vectors $\left(p_{\text {Plan }}, p_{\text {Source }}, p_{\text {Make }}, p_{\text {Deliver }}, p_{\text {Return }}\right)$, more simply denoted $\left(p_{1}, p_{2}, p_{3}, p_{4}, p_{5}\right)$. To reduce the difficulty of the task, experts are asked about the interaction parameters which can be neglected. Thus, only the $I_{12}, I_{13}, I_{14}, I_{15}$ parameters are taken into account between the Plan process performance and all the others. The set of pair-wise comparisons gives:

$$
\begin{aligned}
& p_{\mathrm{Ag}}^{(1,0,1,1,0)}>^{4} p_{\mathrm{Ag}}^{(1,0,1,0,1)}>^{5} p_{\mathrm{Ag}}^{(1,1,0,0,0)}>^{5} p_{\mathrm{Ag}}^{(1,0,0,1,0)} \\
& p_{\mathrm{Ag}}^{(1,0,0,1,0)}>^{3} p_{\mathrm{Ag}}^{(0,0,1,0,0)}>^{4} p_{\mathrm{Ag}}^{(1,0,0,0,0)}>^{2} p_{\mathrm{Ag}}^{(0,1,0,0,0)} \\
& p_{\mathrm{Ag}}^{(0,1,0,0,0)}>^{1} p_{\mathrm{Ag}}^{(0,0,0,1,0)}>^{0} p_{\mathrm{Ag}}^{(0,0,0,0,1)}>^{3} p_{\mathrm{Ag}}^{(0,0,0,0,0)}
\end{aligned}
$$

The system (6) denotes the preference relations between all the situations. The number of considered relations depends on the number of parameters to be determined. The equation system to be solved is given in Appendix 2.

The decision-makers can now aggregate the elementary performances:

$$
\begin{aligned}
& p_{A g}=v_{1} p_{1}+v_{2} p_{2}+v_{3} p_{3}+v_{4} p_{4}+v_{5} p_{5}-\frac{1}{2}\left[I_{12}\left|p_{1}-p_{2}\right|+I_{13}\right. \\
& \left.\left|p_{1}-p_{3}\right|-I_{14}\left|p_{1}-p_{4}\right|\right]=0,53
\end{aligned}
$$

It is also possible to simulate the impact of an improvement of the Source process to validate an action plan, as summarized in Table 7.

- the $p_{2}+$ improvement, which is typical of the continuous Kaizen improvement and allows to gain 0,1 in this case for the Source process performance;

- the $p_{2}++$ improvement, which is typical of the radical Business Process Reengineering and allows to gain 0,4 in this case for the Source process performance.

Note that the cost that constitutes a radical element in the decision-making process, of these two improvements is different.

But naturally, the overall impact is weak, given that:

- the weight (Shapley coefficient) is not very high $\left(\left(v_{2}\right.\right.$ $=0.19$ );

- $\quad$ the interaction $I_{12}$ is high, $I_{12}=0.19$. 
Table 8. Different Improvement Scenarios

\begin{tabular}{|c|c|c|c|c|c|c|}
\hline & $p_{1}$ & $p_{2}$ & $p_{3}$ & $p_{4}$ & $p_{5}$ & $p_{\mathrm{Ag}}$ \\
\hline \hline $\begin{array}{c}\text { Current } \\
\text { state }\end{array}$ & 0,48 & 0,55 & 0,71 & 0,59 & 0,36 & $\mathbf{0 . 5 3}$ \\
\hline $\boldsymbol{p}_{\mathbf{1}+\boldsymbol{\alpha} \boldsymbol{p}_{\mathbf{2}^{+}}}$ & 0,65 & 0,65 & 0,71 & 0,59 & 0,36 & $\mathbf{0 . 6 3}$ \\
\hline
\end{tabular}

It is thus more efficient for the company to jointly improve $p_{1}$ and $p_{2}$, as shown in Table 8 ; i.e. it is better to moderately improve $p_{1}$ and $p_{2}$ rather than to try to significantly improve only $p_{2}$.

\section{CONCLUSION AND PERSPECTIVES}

An approach for the performance expression, measurement and aggregation in a SC context has been proposed in this paper. The focus has been on the overall performance of the prime manufacturer of the SC. A formal framework has been proposed to express the relationships of the prime manufacturer with its suppliers. The overall performance concept allows decision-makers to have one synthetic information instrument that is obtained from the aggregation of elementary expressions, which reflect the behaviours of the involved systems. This overall expression is consistent with global networked organizations, and makes possible the comparison of situations conventionally assessed as "hardly comparable". The major idea of this work is the definition of the SC through a System of Subsystems (SoS), namely a network made of a prime manufacturer and its suppliers. Each subsystem is described in terms of its constituting business processes. The SCOR model has thus been used to describe these sub-systems in a homogeneous way. Formally, the Choquet Integral operator, which takes the interactions between sub-systems into account, provides a better model of the complex relationships between the elementary and the overall performance expressions than the Weighted Mean. Moreover, the consistent multi-criteria MACBETH method has been applied to the performance expressions for the five SCOR processes of a SC, in order to give a structured and sound framework. The approach has been tested on a real-case case study but will now be applied to more industrial experimentations for improvement and refinement. Furthermore, one theoretical perspective is to reflect, first, about a better handling, by means of the $\mathrm{CI}$, of the mutual interactions between the involved subsystems in the SC, in order to, finally, handle and define the overall performance of the SC as a whole.

\section{CONFLICT OF INTEREST}

None declared.

\section{ACKNOWLEDGEMENTS}

The authors would like to express their sincere thank to Vincent Clivillé for his indirect contribution to the paper through fruitful discussions and reference to his previous work.

\section{APPENDIX 1: EXAMPLE OF SYSTEM EQUATION SOLVING}

Notation: $p_{\mathrm{Ag}}^{(0,0,1,0)}$ is the aggregated performance associated to the situation of the SC characterized by the elementary performance vector $(0,0,1,0)$.

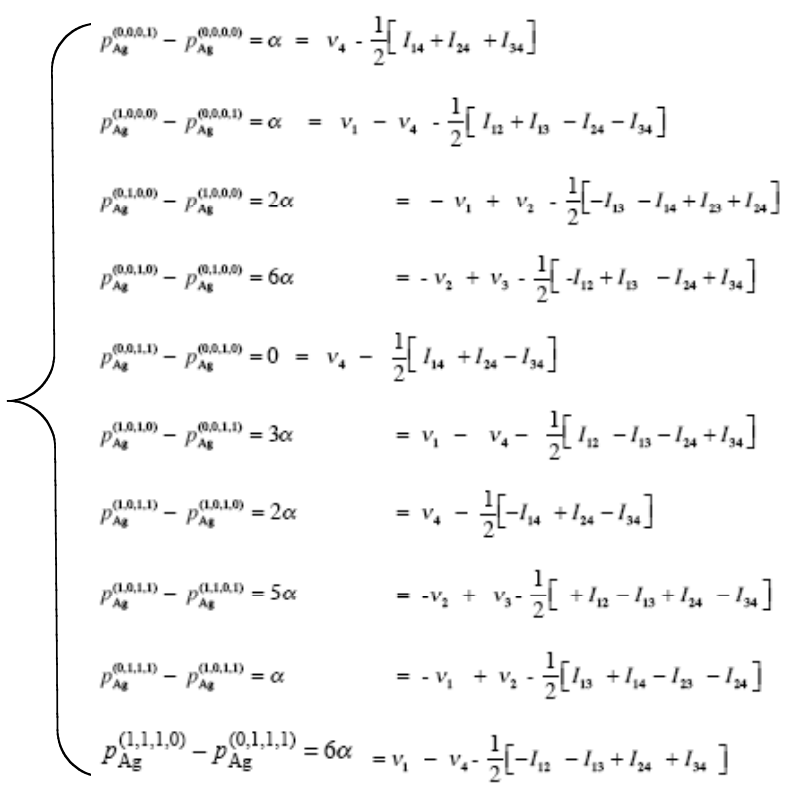

The solution of the system is:

\begin{tabular}{|c|c|c|c|c|c|c|c|c|c|}
\hline $\mathbf{n}_{1}$ & $\mathbf{n}_{2}$ & $\mathbf{n}_{3}$ & $\mathbf{n}_{4}$ & $I_{12}$ & $I_{13}$ & $I_{i 4}$ & $I_{23}$ & $I_{24}$ & $I_{34}$ \\
\hline $9 / 46$ & $12 / 46$ & $23 / 46$ & $2 / 46$ & $4 / 46$ & $2 / 46$ & $4 / 46$ & $6 / 46$ & $-2 / 46$ & $-2 / 46$ \\
\hline$\gg 0,20$ & $\gg 0,26$ & 0,50 & $» 0,04$ & $» 0,09$ & $\gg 0,04$ & $\gg 0,09$ & »0,13 & $\begin{array}{c}\gg- \\
0,04\end{array}$ & $\begin{array}{c}\gg- \\
0,04\end{array}$ \\
\hline
\end{tabular}

\section{APPENDIX 2: CASE STUDY SYSTEM EQUATION SOLVING}

$$
\left\{\begin{array}{l}
p_{\mathrm{Ag}}^{(0,0,0,0,1)}-p_{\mathrm{Ag}}^{(0,0,0,0,0)}=3 \alpha=v_{5}-\frac{1}{2}\left[I_{15}\right] \\
p_{\mathrm{Ag}}^{(0,0,0,1,0)}-p_{\mathrm{Ag}}^{(0,0,0,0,1)}=0=v_{4}-v_{5}-\frac{1}{2}\left[I_{14}-I_{15}\right] \\
p_{\mathrm{Ag}}^{(0,1,0,0,0)}-p_{\mathrm{Ag}}^{(0,0,0,1,0)}=\alpha=v_{2}-v_{4}-\frac{1}{2}\left[I_{12}-I_{14}\right] \\
p_{\mathrm{Ag}}^{(1,0,0,0,0)}-p_{\mathrm{Ag}}^{(0,1,0,0,0)}=2 \alpha=v_{1}-v_{2}-\frac{1}{2}\left[I_{13}+I_{14}+I_{15}\right] \\
p_{\mathrm{Ag}}^{(0,0,1,0,0)}-p_{\mathrm{Ag}}^{(1,0,0,0,0)}=4 \alpha=-v_{1}+v_{3}-\frac{1}{2}\left[-I_{12}-I_{14}-I_{15}\right] \\
p_{\mathrm{Ag}}^{(1,0,0,1,0)}-p_{\mathrm{Ag}}^{(0,0,1,0,0)}=3 \alpha=v_{1}-v_{3}+v_{4}-\frac{1}{2}\left[I_{12}+I_{15}\right] \\
p_{\mathrm{Ag}}^{(1,1,0,0,0)}-p_{\mathrm{Ag}}^{(1,0,0,1,0)}=5 \alpha=v_{2}-v_{4}-\frac{1}{2}\left[-I_{12}+I_{14}\right] \\
p_{\mathrm{Ag}}^{(1,0,1,0,1)}-p_{\mathrm{Ag}}^{(1,1,0,0,0)}=5 \alpha=-v_{2}+v_{3}+v_{5}-\frac{1}{2}\left[I_{12}-I_{13}-I_{15}\right] \\
p_{\mathrm{Ag}}^{(1,0,1,1,0)}-p_{\mathrm{Ag}}^{(1,0,1,0,1)}=6 \alpha=-v_{2}+v_{3}-v_{4}-\frac{1}{2}\left[-I_{12}+I_{13}-I_{14}\right] \\
p_{\mathrm{Ag}}^{(1,1,1,1,1)}-p_{\mathrm{Ag}}^{(0,0,0,0,0)}=1=v_{1}+v_{2}+v_{3}+v_{4}+v_{5}
\end{array}\right.
$$

\section{REFERENCES}

[1] B. Burnes and S. New, "Understanding supply chain improvement," Eur. J. Purch. Supply Manage., vol. 2, no. 1, pp. 21-30, 1996

[2] D. Knoppen, E. Christiaanse, and M. Huysman, "Supply chain relationships: Exploring the linkage between inter-organisational adaptation and learning," J. Purch. Supply Manage., vol. 16, no. 3, pp. 195-205, 2010 
[3] D. Simchi-Levi, P. Kaminsky, and E. Simchi-Levi, Designing and Managing the Supply Chain: Concepts Strategies and Case Studies. Irwin/McGraw-Hill: Homewood, IL/New York, 1999.

[4] D. M. Lambert and M. C. Cooper, "Issues in supply chain management," Ind. Market. Manage., vol. 29, pp. 65-83, 2000.

[5] A. De Kok and S. Graves, Eds., Supply Chain Management: Design, Coordination, and Operation, $1^{\text {st }}$ ed. Elsevier: Amsterdam, 2003.

[6] G. A. Akyuz, and T. E. Erkan, "Supply chain performance measurement: a literature review," Int. J. Prod. Res., vol. 48, no. 17, pp. 5137-5155, 2010.

[7] M. Barut, W. Faisst, and J. J. Kanet, "Measuring supply chain coupling: an information system perspective," Eur. J. Purch. Supply Manage., vol. 8, no. 3, pp. 161-171, 2002.

[8] J. B. Ayers. Handbook of Supply Chain Management, ser. APICS Series on Resource Management, Saint Lucie Press: Alexandria, Virginia, USA, 2000.

[9] M. J. Meixell and V. B. Gargeya, "Global supply chain design: A literature review and critique," Transp. Res. Part E. Logist. Transport. Rev., vol. 41, no. 6, pp. 531-550, 2005.

[10] X. Luo, C. Wu, D. Rosenberg, and D. Barnes, "Supplier selection in agile supply chains: An information-processing model and an illustration," J. Purch. Supply Manage., vol. 15, no. 4, pp. 249-262, 2009.

[11] D. Wu and D. L. Olson, "Supply chain risk, simulation, and vendor selection," Int. J. Prod. Econ., vol. 114, no. 2, pp. 646-655, 2008.

[12] K.-C. Tan, "A framework of supply chain management literature," Eur. J. Purch. Supply Manage., vol. 7, no. 1, pp. 39-48, 2001.

[13] C. S. Tang, "Perspectives in supply chain risk management," Int. J. Prod. Econ., vol. 103, no. 2, pp. 451-488, 2006.

[14] S. Li, B. Ragu-Nathan, T. S. Ragu-Nathan, and S. Rao, "The impact of supply chain management practices on competitive advantage and organizational performance," Omega, vol. 34, no. 2, pp. 107-124, 2006.

[15] S. W. Kim, "Organizational structures and the performance of supply chain management," Int. J. Prod. Econ., vol. 106, no. 2, pp. 323-345, 2007.

[16] A. Villa, "Introducing some supply chain management problems," Int. J. Prod. Econ., vol. 73, no. 1, pp. 1-4, 2001.

[17] H. Min and G. Zhou, "Supply chain modelling: past, present and future," Comput. Ind. Eng., vol. 43, pp. 231-249, 2002.

[18] SCOR 10.0: Overview Booklet, Supply Chain Council editions. [Online]. Available: http://supply-chain.org/f/SCOR-OverviewWeb.pdf

[19] U. S. Bititci, P. Suwignjo, and A. S. Carrie, "Strategy management through quantitative modelling of performance measurement systems," Int. J. Prod. Econ., vol. 69, no. 1, pp. 15-22, 2001.

[20] F. T. S. Chan, "Performance measurement in a supply chain," Int. J. Adv. Manuf. Tech., vol. 21, pp. 534-548, 2003.

[21] B. Fynes, S. de Búrca, and J. Mangan, "The effect of relationship characteristics on relationship quality and performance," Int. J. Prod. Econ., vol. 111, no. 1, pp. 56-69, 2008.

[22] A. C. Böhm, H. P. Leone, and G. P. Henning, "Industrial supply chains: Performance measures, metrics and benchmarks," In: 17th European Symposium on Computer Aided Process Engineering, ser. Computer Aided Chemical Engineering, V. Plesu and P. S. Agachi, Eds. Elsevier: Amsterdam 2007, vol. 24, pp. 757-762.

[23] S. S. Nudurupati, U. S. Bititci, V. Kumar, and F. T. S. Chan, "State of the art literature review on performance measurement," Comput. Ind. Eng., vol. 60, no. 2, pp. 279-290, 2011.

[24] B. M. Beamon, "Supply chain design and analysis: Models and methods," Int. J. Prod. Econ., vol. 55, no. 3, pp. 281-294, 1998.

[25] W. H. Hausman, "Supply chain performance metrics," In: T. P. Harrison, H. L. Lee, and J. J. Neale, Eds. The Practice of Supply Chain Management: Where Theory and Application Converge, Springer Science \& Business Media: New York, NY, 2004, pp. 6673.

[26] B. J. Angerhofer and M. C. Angelides, "A model and a performance measurement system for collaborative supply chains," Decis. Support Syst., vol. 42, no. 1, pp. 283-301, 2006.

[27] A. Gunasekaran, K.-H. Lai, and T. C. E. Cheng, "Responsive supply chain: A competitive strategy in a networked economy," Omega, vol. 36, no. 4, pp. 549-564, 2008.

[28] U. S. Bititci, "Modelling of performance measurement systems in manufacturing enterprises," Int. J. Prod. Econ., vol. 42, pp. 137147, 1995.
[29] V. Clivillé, L. Berrah, and G. Mauris, "Quantitative expression and aggregation of performance measurements based on the MACBETH multi-criteria method," Int. J. Prod. Econ., vol. 105, no. 1, pp. 171-189, 2007.

[30] A. Neely, "The performance measurement revolution: why now and what next?" Int. J. Oper. Prod. Manag, vol. 19, no. 2, pp. 205228, 1999.

[31] P. Folan and J. Browne, "A review of performance measurement: Towards performance management," Comput. Ind., vol. 56, no. 7, pp. 663-680, 2005.

[32] V. Clivillé and L. Berrah, "Overall performance measurement in a supply chain: towards a supplier-prime manufacturer based model," J. Intell. Manuf., vol. 22, no. 2, pp. 1-11, 2011.

[33] ISO 9001: 2008, International Standards Organization. [Online]. Available: www.iso.org

[34] R. L. Ackoff, "Towards a system of systems concepts," Manage. Sci., vol. 17, no. 11, pp. 661-671, 1971.

[35] M. W. Maier, "Architecting principles for systems-of-systems," Syst. Eng., vol. 1, no. 4, pp. 267-284, 1998.

[36] A. Gorod, G. Ryan, S. Brian, and B. John, "System of systems management: A network management approach," In: Proceedings of the IEEE International Conference on System of Systems Engineering, San Antonio, Texas, April 2007, pp. 1-5.

[37] I. N. Caddy and M. M. Helou, "Supply chains and their management: Application of general systems theory," J. Retailing Consum. Serv., vol. 14, no. 5, pp. 319-327, 2007.

[38] C. Lohman, L. Fortuin, and M. Wouters, "Designing a performance measurement system: A case study,” Eur. J. Oper. Res., vol. 156, no. 2, pp. 267-286, 2004.

[39] D. Diakoulaki, G. Mavrotas, and L. Papagyannakis, "A multicriteria approach for evaluating the performance of industrial firms," Omega, vol. 20, pp. 467-474, 1992.

[40] S. Globerson, "Issues in developing a performance criteria system for an organisation," Int. J. Prod. Res., vol. 23, no. 4, pp. 639-646, 1985.

[41] L. Berrah, G. Mauris, and F. Vernadat, "Information aggregation in industrial performance measurement: rationales, issues and definitions," Int. J. Prod. Res., vol. 42, no. 20, pp. 4271-4293, 2004.

[42] J. L. Marichal, "An axiomatic approach of the discrete Choquet integral as a tool to aggregate interacting criteria," IEEE T. Fuzzy Syst., vol. 8, pp. 800-807, 2000.

[43] J. Figueira, S.Greco, and M. Ehrgott, Eds., Multiple Criteria Decision Analysis. State of the art Surveys, Springer: Berlin 2005.

[44] T. Saaty, "The analytical hierarchy and analytic network process for the measurement of intangible criteria and for decisionmaking," In: J. Figueira, S. Greco, and M. Ehrgott, Eds. Multiple Criteria Decision Analysis. State of the Art Surveys, Springer: Berlin 2005, pp. 345-407.

[45] P. Suwignjo, U. Bititci, and A. Carrie, "Quantitative models for performance measurement system," Int. J. Prod. Econ., vol. 64, no. 1-3, pp. 231-241, 2000.

[46] T. Schoenherr, V. M. R. Tummala, and T. P. Harrison, “Assessing supply chain risks with the analytic hierarchy process: Providing decision support for the off shoring decision by a bus manufacturing company," J. Purch. Supply Manag., vol. 14, no. 2, pp. 100$111,2008$.

[47] C. Bana e Costa, J. M. De Corte, and J. C. Vansnick, "On the mathematical foundations of MACBETH," In: J. Figueira, S. Greco, and M. Ehrgott, Eds. Multiple Criteria Decision Analysis: State of the Art Surveys, Springer: Berlin 2005, pp. 409-437.

[48] C. Labreuche and M. Grabisch, "The Choquet integral for the aggregation of interval scales in multicriteria decision making," Fuzzy Set. Syst., vol. 137, no. 1, pp. 11-26, 2003.

[49] L. Berrah and V. Clivillé, "Towards an aggregation performance measurement system model in a supply chain context," Comput. Ind., vol. 58, no. 7, pp. 709-719, 2007.

[50] J. Boardman and B. Sauser, "Systems of systems - the meaning of of," In: Proceedings of the 2006 IEEE/SMC International Conference on System of Systems Engineering, IEEE: Los Angeles, CA, April 2006, pp. 4-10.

[51] S. H. Huang, S. K. Sheoran, and H. Keskar, "Computer-assisted supply chain configuration based on supply chain operations reference (SCOR) model," Comput. Ind. Eng., vol. 48, no. 2, pp. 377394, 2005. 
[52] F. Persson, "SCOR template-a simulation based dynamic supply chain analysis tool," Int. J. Prod. Econ., vol. 131, no. 1, pp. 288294, 2011.

[53] D. H. Krantz, R. D. Luce, P. Suppes, and A. Tversky, Foundations of Measurement, Vol. I., Additive and Polynomial Representations. Academic Press: New York, 1971.

[54] M. Grabisch, J.-L. Marichal, R. Mesiar, and E. Pap, "Aggregation functions," In: Encyclopedia of Mathematics and its Applications. Cambridge University Press: Cambridge vol. 127, 2009.

[55] M. Grabisch, J.-L. Marichal, R. Mesiar, and E. Pap, "Aggregation functions: Means," Inform. Sci., vol. 181, pp. 1-22, 2011

[56] I. Bloch, "Information combination operators for data fusion: a comparative review with classification," IEEE Trans. Syst. Man Cybern. A, vol. 26, no. 1, pp. 52-67, 1996.
[57] S. A. Melnyk, D. M. Stewart, and M. Swink, "Metrics and performance measurement in operations management: dealing with the metrics maze," J. Oper. Manag., vol. 22, no. 3, pp. 209-218, 2004.

[58] L. Berrah, G. Mauris, A. Haurat, and L. Foulloy, "Global vision and performance indicators for an industrial improvement approach," Comp. Ind., vol. 43, no. 3, pp. 211-225, 2000.

[59] L. Fortuin, "Performance indicators, why, where and how?" Eur. J. Oper. Res, vol. 34, pp. 1-9, 1988.

[60] C. Bana e Costa and J. C. Vansnick, "Applications of the MACBETH approach in the framework of an additive aggregation model," J. Multi-Criteria Decis. Anal., vol. 6, pp. 107-114, 1997.

[61] M. Grabisch, "k-ordered discrete fuzzy measures and their representation," Fuzzy Set. Syst., vol. 92, pp. 167-189, 1997.

[62] A. Gunasekaran, C. Patel, and R. E. McGaughey, "A framework for supply chain performance measurement," Int. J. Prod. Econ., vol. 87, no. 3, pp. 333-347, 2004.

(C) Berrah and Vernadat; Licensee Bentham Open.

This is an open access article licensed under the terms of the Creative Commons Attribution Non-Commercial License (http://creativecommons.org/licenses/by-nc/3.0/) which permits unrestricted, non-commercial use, distribution and reproduction in any medium, provided the work is properly cited. 